\title{
Aristotle's Method for Determining the Nature of Happiness
}

\author{
Gillian Brock \\ University of Auckland, New Zealand
}

Statement of objectives for this paper

In this paper I shall be concerned with the method Aristotle uses in the inquiry into the nature of happiness in the Nicomachean Ethics. Through analysis of some of the method's features, it will be seen that labelling it "the onion approach to developing and fleshing out a hypothesis" will be appropriate. I shall show how Aristotle derives a set of necessary conditions and a set of other criteria, or reliable indicators, which any adequate account of the nature of happiness must meet. There are definite benefits to understanding the strategy in these terms. Having derived a set of criteria which an adequate account must fulfill, we are in a position to examine which of the two rival hypotheses about the nature of happiness best satisfies the criteria. The life of theoretical study emerges as the clear winner at meeting the criteria Aristotle himself imposes on an adequate account.

\section{Aristotle's ethical method: an overview of the onion approach}

Aristotle might not appear, prima facie, to have any terribly systematic method in The Nicomachean Ethics (henceforth NE). ${ }^{1}$ Ethics not being a science, it cannot have an exact method, or so he continually maintains. Nevertheless, for all his protestations, there is a discernible pattern to the inquiry which I shall examine and baptize as "the onion approach to developing and fleshing out a hypothesis." The onion approach proceeds roughly as follows:

Aristotle starts by collecting data concerning the nature of happiness (the central subject under inquiry in the NE) and human nature.

The version of the Nicomachean Ethics I have used is the translation by Terence Irwin (Indiana: Hackett, 1985). 
(2) Through careful exegesis of the data, he then attempts to discern the kernel of truth embedded in the data in order to get to a first principle. (He argues that the way of sorting through the data enjoys a claim to epistemological superiority.)

(3) From the findings of step (2), he compiles a list of requirements, or necessary conditions, an adequate account of happiness must fulfill.

(4) He then tests the view as so far developed against fresh data. This testing yields new insights about the hypothesis developed.

(5) These new insights suggest other conditions which should be satisfied by an adequate view. These new conditions will be reliable indicators of an adequate account of happiness rather than fully fledged necessary conditions. (This is so because of the lower epistemological status of the new conditions.)

(6) There is some continual iteration of (4) and (5) until a candidate is found which satisfies more of the necessary conditions and reliable indicators than any other rival view.

In order to appreciate the epistemological attractiveness of this approach, it will be instructive to consider the following passage:

When some object that what everything aims at is not good, surely there is nothing in what they say. For if things seem good to all, we say they are good; and if someone undermines confidence in these, what he says will hardly inspire more confidence in other things. For if only beings without understanding desired these things, there would be something in the objection; but if intelligent beings also desire them, how can there be anything in it? (NE $10,1172 \mathrm{~b} 35$ - $1173 \mathrm{a} 2$ emphasis mine). 
This passage highlights several features of interest:

(i) The fact that all intelligent beings have the same opinions is some reliable yardstick by which to measure truth.

(ii) If all agree that something appears to be good, we are justified in inferring that something is good. For Aristotle, then, total agreement about intersubjective appearances legitimates inferences about objectivity or truth (a very Kantian insight).

(iii) That which everyone believes to be true has more credibility than that which no-one believes to be so. If we deny that the fact that there is widespread agreement about certain beliefs has any bearing on truth, whatever other bench mark is to be introduced will have less credibility attached to it. A huge burden of proof falls on those who maintain such beliefs are no reliable measure of truth.

(iv) Because our descriptions of things are inspired by the way things seem to us and, because total agreement about the way things seem allows us to infer that those descriptions accurately describe the way things are, our ordinary language contains a wealth of ontological insights. Thus mining ordinary language for insights can also be a particularly reliable source of data.

(v) From (ii) and (iv), we can see that using the data of common opinions which enjoy complete unanimity and using data about the way we use ordinary language are two highly reliable sources. These two sources have a strong claim to being authoritative, for Aristotle.

We can now appreciate why the onion approach is epistemologically attractive. The core requirements are derived by consid- 
ering various proposals and rejecting or accepting aspects of them on the basis of ordinary language usage and very widely shared other common beliefs. As was concluded in (v), the results of this sorting procedure will occupy a privileged epistemic status. The analysis gives rise to a minimal set of requirements or necessary conditions which an adequate account must fulfill. These provide the anchor or core of the account. After the core requirements (including the first principle) have been established, through the examination of further data, other 'layers' of insights can be added to the view on a coherence basis. In these analyses he is far more dependent on his own intuitions in discerning truth. This is quite permissible, since once the account has been firmly rooted by the core, one need worry only about consistency in adding the layers.

I turn now to consider in more detail the onion approach to developing a view on the nature of the ultimate good, eudaimonia. I shall first consider the necessary conditions which constitute the privileged epistemic position of the core.

The core

There are two distinct sources of input which are drawn upon to arrive at the first principle, namely, common opinions and metaphysical views. (Aristotle acknowledges that we have a first principle only after he discusses both categories - see NE 1098b.) I turn now to consider the input from the two sources in turn.

\section{Canvassing firom common opinion}

In this category the argument proceeds dialectically. Aristotle examines some opinions about the best life and the highest good but rejects or accepts them on the basis of other very widely held popular opinions (shared by both the intelligent and the vulgar) and ways in which we use ordinary language.

He deals first with the opinion that the best life consists in the life of gratification. This proposal is rejected on the grounds that such a life is insufficiently free. (When the reason is given it is unclear whether what is wrong with this life is that it fails to express freedom, or whether it is inadequate because it is not the 
result of a free choice, or both, but let us ignore this ambiguity.) Furthermore, such a life dedicated to gratification of pleasures is not fitting for a human life but rather for brutes (NE 1095b19-22). Next up for consideration is the life of honor. Such a life is rejected on the basis that it is too superficial, too dependent on others and thus not sufficiently intrinsic to the person. Moreover, such a life would not accord well with our widely shared intuition that the good is "something of our own and hard to take from someone" (NE 1095b25). It appears, furthermore, that those who pursue honor aim to be honored by intelligent people explicitly for their virtue. But mere possession of the state of virtue alone is insufficient, for someone could possess virtue but be inactive his whole life or suffer horrendous misfortune, and such a life would not be deemed happy by anyone. Thus mere possession of virtue without any exercise of that virtue is rejected because happiness has to be an activity. The moneymaker's life is rejected on the grounds that it is not chosen for itself but rather as a means to something further. Such a life is chosen for the sake of something else and the good we are seeking is believed to be choiceworthy in itself.

In dismissing the life of the money-maker, significant issues are introduced and these call for closer inspection. The discussion resumes at NE 1097a24 (after a brief detour through a discussion of why the form of the good cannot be a serious contender in the search for the best life). The good is said to be that for the sake of which all other things are done, but then he leaves it open how many of these there can be: "And so, if there is some end of everything that is pursued in action, this will be the good pursued in action" (NE 10927a22-24). Aristotle then seems to leave the door open for the possibility of there being more than one good which is aimed at.

This talk of aiming at ends leads Aristotle to a discussion of comparative "completeness": an end pursued in itself is said to be more complete than an end pursued for something else. Thus we get the notion of degrees of completeness. The notion of unconditional completeness would mean that such an end is always choiceworthy in itself and never for some other end. Now if only one end is complete, that will be the good, and if more than one end is complete, the most complete end will be the good. Happi- 
ness is always chosen for itself: no one ever chooses happiness for anything else.

The complete good seems to be self-sufficient. "We regard something as self-sufficient when all by itself it makes a life choiceworthy and lacking nothing; and that is what we think happiness does" (NE 1097bl5). We do not believe that any addition can make happiness more choiceworthy. This is so because happiness is not one good among many.

Before going on to consider the next source of input, I shall summarize the requirements found to be necessary for identifying happiness. Taken in the order in which a criterion was discovered rather than any order signifying degrees of importance, canvassing common opinion the following information is revealed about happiness:

(RI) The happy life must express freedom.

(R2) It must be fitting for a human.

(R3) The good which is happiness is not superficial.

(R4) The good is something we intuitively believe is hard to take from someone.

(R5) The good implies an activity not simply the possession of a capacity or state.

(R6) External goods such as good fortune seem in some way to be relevant to happiness.

(R7) No-one chooses happiness for anything other than itself - it is intrinsically desirable.

(R8) The good (or goods if there is more than one), is that for the sake of which other things are done.

(R9) The good is the most complete end. 
(R10) The good is most choiceworthy. There is nothing which can be added to the good which will make it more choiceworthy.

(RII) The good is self-sufficient, that is, all by itself it makes a life most choiceworthy.

One comment is worth making before proceeding: (R4) and (R6) might appear to be incompatible - this prima facie incompatibility will be resolved further on.

\section{Input from metaphysical commitments}

Happiness is to be identified with the proper and special function of humans (NE 1,7,1097b22-1098a3). Human beings' distinctive nature is now of concern to the inquiry. The argument at NE $1,7,1098$ al3-18 proceeds as follows:

(P1) If something has a function, then the good for that thing depends on that function.

(P2) Humans have the special function of some sort of life of action of the part of the soul which expresses or requires reason (NE 1,1098a2-4).

(P3) Each function is completed well when its completion expresses the proper virtue (NE 1,1098a 15-16).

Therefore, the human good is the soul's activity that expresses virtue (NE 1,1098al6-17).

He continues the argument at NE 1, 1098al3-18. The human good is supposed to be an activity of the soul in accordance with virtue and if there is more than one virtue, in accordance with the best and most complete virtue in a complete life (NE 1,1098al318). This sets the stage for a search for the best and most complete virtue. 
From these arguments we can add the following requirements to the list: 2

(R12) Happiness is the soul's activity that expresses virtue and if there is more than one virtue, the good will express the best and most complete virtue.

(R13) It is to be found in a complete life.

(R14) It realizes some distinctive element in human nature.

(R15) The virtue of a human being will be that state which makes him perform his function well.

((RI2) is considered by Aristotle to constitute a first principle, but as my analysis suggests, it is simply another necessary condition in the set of necessary conditions.)

Armed with the list of requirements collected so far, Aristotle can begin with the next phase: Testing the core view as so far developed against new data. (Just to make it clear, (RI)-(R15) constitute the core of his view on happiness. Any adequate account of happiness must embrace at least these requirements.)

\section{Testing by examining new data}

1. There is a common classification of goods into three types: external goods, goods of the soul and goods of the body. Goods of the soul are commonly recognized as the most valuable. The account thusfar arrived at preserves this view i.e. this datum is compatible with (R1) through (R15), and more particularly with (R12).

2 Why is the definition of happiness just another necessary condition? The definition of happiness is a statement about the nature of happiness which all agree is the case, and that is a necessary and sufficient condition for its being a necessary condition of an adequate account of happiness. So, though Aristolle considers the definition of happiness to be a first principle, as I have set things up in this paper, it is just one among several necessary conditions which have the same status he accords his lirst principle. 
2. The view accords with the belief that the end is a sort of living well and doing well in action.

3. “... all the features that people look for in happiness appear to be true of the end described in our account" (NE 1098b22) it is claimed:

3a. The account agrees with those who maintain that happiness is activity expressing a particular virtue. It is activity which is of the highest worth, rather than simply possessing a state. The prizes are not awarded in the Olympics for simply looking strong but actually demonstrating in activity that strength better than the competition.

3b. The life of the happy man will also be pleasant (NE 1, 1099a7). But the pleasure is not something extra and in addition to the life of virtue, rather that pleasure is intrinsic to that life because actions expressing the virtues are pleasant in themselves. Happiness is said to be the "best, finest and most pleasant" thing in the world. (The excellent person who has good judgement agrees with these conclusions (NE 1099a23-25) and so this becomes a highly reliable indicator of the good life.)

3c. Happiness requires external goods because certain resources will be required in order to perform virtuous actions. Happiness also depends to some extent on a certain amount of good fortune: having good birth, good children, friends and beauty. But if happiness depended too heavily on external goods, a person's happiness could fluctuate erratically and this does not accord with our intuition that happiness is enduring and not prone to fluctuation. Although a modicum of these external goods might be necessary, it is virtue which is the controlling element: “.... it is the activities express- 
ing virtue that control happiness, and the contrary activities that control its contrary" (NE 1100b911). No other human activity has the same permanence as virtuous activity. The best virtues will be the ones we can devote ourselves to more fully and continually (NE 1100bl5-17).

From this testing step, a few more criteria must be added to our list as highly reliable indicators. Some of these are highly reliable indicators if not fully fledged necessary conditions because they are thought to be important by excellent people, but not all people.

(I16) Happiness will be some good of the soul.

(I17) Happiness is a sort of living well and doing well in action.

(I18) It is most pleasant.

(I19) Happiness should not depend too heavily on external goods.

(120) Virtue is the controlling element of happiness.

(I21) Happiness will consist in those activities we can engage in most fully and continuously.

The initial testing phase having turned out well, we need to go on to develop the view more fully, that is, we need to look for the single virtue which is best and most complete. (Aristotle seems to be abandoning the model earlier hinted at as a possibility of happiness as consisting of a number of virtues.) The hunt is on for the best and most complete virtue. We know what the criterion for most complete is, but Aristotle has not yet explicitly discussed the criterion for judging the best virtue. 
With our work clearly set out for us, it is with enthusiasm that we might turn to books two through nine in search of the best and most complete virtue. But Aristotle does not talk in terms of the best and most complete virtue again until book ten. In book six he does compare some virtues of thought. Wisdom is clearly thought to be better than intelligence. At NE 1141a20-28 we get several arguments as to why intelligence is inferior to wisdom.

(1) The most excellent science must be of the best things. Human beings are not the best things in the universe. Therefore, the most excellent science is not the science of (the good for) man.

(2) The objects of knowledge involved in wisdom are by necessity eternally true whereas the objects of knowledge involved in intelligence are only contingently true. The science which is engaged in discovering eternal truths is superior to the science concerned with mere relativized or contingent truths. Therefore, wisdom is superior to intelligence.

(3) Some beasts can be said to have intelligence. No beasts can be said to have wisdom. What we share with beasts is of lesser value than what is distinctive of humans. Therefore, wisdom is superior to intelligence.

Further down at $1141 \mathrm{bl}-4$ we get another argument along similar lines.

(4) Wisdom is concerned with what is by nature most honorable. What is concerned with what is by nature most honorable is better than what is concerned with things not as honorable. Therefore, wisdom is better than intelligence. 
From this set of arguments it might seem that we have found our best virtue of thought, namely wisdom, but we are not yet in a position to know this since we still have not been given an explicit criterion for judging the best virtue. I turn now to consider the discussion in book ten to see what help it can give in our search for the best virtue.

At NE 1176a33, Aristotle gives us what purports to be a recapitulation of his former findings about happiness. The first three features of happiness are indeed a recap from previous findings:

Happiness is not a state, but rather an activity.

Happiness is most choiceworthy.

Happiness is most self-sufficient.

But after these three features are discussed we turn to what appears to be very different material. Aristotle considers the popular suggestion that happiness is a state of amusement because it appears that many people with supreme power spend their leisure time on amusements. Aristotle then supplies a battery of arguments against this suggestion. Methodologically, what is going on here is that the view developed thusfar is tested against new data. Although the new data fails to pass the relevant tests, it reveals a new layer of insights to add to "the onion" which has thusfar emerged. I turn then to consider Aristotle's reasons for rejecting the new datum:

(1) Amusement causes more harm than benefit because amusement causes neglect of our bodies and possessions.

(2) What people who hold supreme power do does not constitute good evidence for what is best. Virtue and understanding, the sources of excellent activities are not dependent on having supreme power (NE 1176bl8).

(3) These powerful people do not know pure and civilized pleasures and therefore they resort to bodily pleasures. Different things appear honorable to base and decent 
people. Those things which are really honorable and pleasant are those things which appear so to the excellent person.

(4) It would be absurd if our lifelong efforts aimed at amusing ourselves. Serious work aimed only at amusement is stupid and puerile. It seems correct to amuse ourselves in order that we can do something serious and "it is because we cannot toil continuously that we require relaxation" (NE 1177b34-35). "The activity of what is better is superior, and thereby has more the character of happiness" (NE 1177a6-7).

(5) Relaxation is good as a means or as preparation for activity.

From the previous discussion it seems that Aristotle is suggesting three more reliable indicators of the highest good:

(I22) The good must not cause more harm than benefit: it must not cause the neglect of our bodies and possessions.

(I23) The pleasures to be experienced from happiness are of a pure and civilized type.

(I24) The good must be involved with serious matters. The character of happiness is more adequately captured by the pursuit of serious things.

At NE 1177al0-12 Aristotle puts forward an argument for the highest good:

P1. "If happiness is activity expressing virtue, it is reasonable for it to express the supreme virtue, which will be the virtue of the best things" (NE 1177al0-12). 
P2. The best thing (in us) is understanding, since the objects of understanding are the supreme objects of knowledge (NE 1177a20).

P3. The virtue associated with understanding is the activity of study.

Therefore, the activity of theoretical study constitutes complete happiness.

It is here that Aristotle's criterion for judging the best virtue is revealed: the best virtue (for humans) will correspond to the best element in human beings. Then Aristotle cites a list of reasons why the activity of theoretical study is best. Some of these reasons satisfy requirements (necessary conditions) originally laid down and others satisfy reliable indicators rather than actual requirements. Some of these reasons are completely new:

a) We can engage in theoretical study most continuously, that is, it satisfies (I21). Theoretical study is the most continuous activity, "since we are more capable of continuous study than any continuous action" (117a20).

b) It is most pleasant, so it satisfies (I18). Moreover, philosophy is said to have remarkably pure and firm pleasures, so it satisfies (I23) too.

c) It is most self-sufficient. It might appear that the activity of theoretical study satisfies (RI1). On closer inspection, however, it appears that the meaning of the concept "self-sufficient" here has shifted quite remarkably from its meaning in (R11). Formerly, self-sufficiency was described differently: "we regard something as self-sufficient when all by itself it makes a life choiceworthy and lacking nothing" (NE 1097bl5). Now self-sufficiency seems to mean that the activity can be done without the need for other people (although he concedes perhaps this can be done better with others). Thus this notion of self-sufficiency introduces a 
new reliable indicator rather than the activity of theoretical study satisfying an old one.

d) It aims at no end beyond itself. Study is said to be intrinsically desired because of itself alone, since it has no result beyond having studied. He says: "But from the virtues concerned with action we try to a greater or lesser extent to gain something beyond the action itself" (NE 1177b 1-4). Now it is not clear what sorts of things he has in mind when he says we try to gain something beyond the action itself. In other places he is explicit that we should do actions for their own sakes to be doing them virtuously (e.g., NE 1105a3233) so it is not obvious what we are trying to gain beyond the action itself. Perhaps he means that when we do virtuous practical activities, in addition to doing things for their own sakes, we also attempt to accomplish something by doing them in the sense that we wish to succeed in bringing about some change to some state of affairs. In the activity of theoretical study such attempts at success are no part of the process, at least not in the same sense.

e) It involves leisure. Here is a new criterion altogether. By "leisure" it seems what is meant is "peace-time," i.e.. a condition of not being at war with other nations. It is said that the virtues concerned with action require war, trouble or politics in order to manifest themselves. Those actions expressing virtues in war are fine but they require trouble, they are not only intrinsically but also instrumentally desirable, since they aim at some end beyond the action itself. These actions are thus choiceworthy for some end other than themselves and so are not most choiceworthy. The activity of theoretical study by contrast aims at no end beyond itself. It has its own proper pleasure which encourages the activity, for no end other than engaging in that activity. It thus satisfies (R7), (R8), (R9) and (R10). Satisfying 
(R7) through (R10), where the life of practical activity expressing the virtues of character and intelligence fails, is an important finding in this investigation. Requirements (R7) - (R10) are part of the "core", i.e., these are necessary conditions for a minimally adequate account of the nature of happiness. The fact that the life of theoretical activity satisfies them is a huge datum in favor of its giving the preferable account of the nature of happiness.

f) It is a god-like life. This might seem to be a new twist to the story told thusfar.

"Such a life would be superior to the human level. For someone will live it not in so far as he is a human being, but in so far as he has some divine element in him. And the activity of this divine element is as much superior to the compound. Hence if understanding is something divine in comparison with a human being, so also will the life that expresses understanding be divine in comparison with human life." (NE 1177b2632).

One might have the following worry: Before this, the focus was on establishing what a specifically human life would look like - what sort of life would be most suitable for humans. It now appears that such an investigation misses the mark and what we ought to be investigating is what sort of life would be proper for some divine being. But this worry can be allayed fairly easily. It is indeed a necessary condition that the highest good must establish what sort of life would be most suitable for humans. However, what we have found is that the best sort of life for humans has some aspects to it which overlap partially with the best sort of life for the gods. The reason for this partial overlap is that humans have a divine element "in" them. The happy life is not required to resemble a god-like life uncon- 
ditionally. Rather, in so far as our characteristic activity will correspond to the best thing in us, and, in those respects in which the best thing in us is god-like, our lives will be god-like in those respects.

h) It realizes the supreme element in human nature. We have been enjoined to search for the best and most complete virtue. We have been informed that the best virtue will correspond to the best part in us, so this should be no revelation at this stage.

From this discussion a few more reliable indicators are suggested:

(125) The best virtue (for humans) will correspond to the supreme element in humans.

(I26) The highest good or best activity constituting happiness will be self-sufficient ${ }_{2}$, not in the sense articulated in (R11), but rather in the sense that this activity can be done without needing other people.

(I27) The highest good aims at no end beyond itself.

(I28) The highest good will require peace-time or leisure.

(I29) The highest good will (in some respects) emulate a god-like life.

The benefits of understanding Aristotle's strategy in these terms

We are now in a position to address the notoriously difficult problem of reconciling the apparently distinct accounts of the nature of happiness to be found in NE. ${ }^{3}$ Space does not allow me to

3 For more on this problem see, for instance, Kathleen Wilkes, "The Good Man and the Good for Man in Aristotle's Ethics", Mind 87 (1978), 553-571; J. L. Ackrill, "Aristotle on Eudaimonia," the Dawes Hicks Lecture on Philosophy which appeared in the Procesedings of the British Academ, October 1974; Amelie Oksenberg Rorty, "The Place of Contemplation in Aristotle's Nicomachean Ethics," Mind 87 
rehearse too many details of the problem, but the basic point, at any rate, can be simply put. Aristotle gives two distinct and incompatible accounts of the nature of happiness in NE. In the earlier part of NE (especially book IV) he tells us that a happy life is one spent engaging in practical activity in accordance with virtues of character and intelligence. However, in book $\mathrm{X}$ he tells us that a happy life is one spent engaging in the activity of theoretical study (quite different from a life of practical activity in accordance with intelligence, since, for one thing, the objects of theoretical study are entirely different). As Aristotle describes them, the two kinds of lives are mutually exclusive, for several reasons including, for instance, that the life spent engaging in theoretical contemplation is one spent quite apart from others in a way that the life embracing practical virtues cannot be.

Of course, one can try to redescribe the two lives so that they can be made compatible, ${ }^{4}$ but these attempts will all have the worrisome problem of departing from Aristotle's actual text a fair bit. As I argue next, if we are to look solely at which account satisfies more of the necessary conditions and reliable indicators, a clear winner between these rival views emerges. (Although it will be more important to satisfy necessary conditions rather than reliable indicators and the satisfying of the former should be weighted more heavily than the satisfying of the latter, such added complexity is not necessary since, as will be seen, the competition is not even close.) This procedure of seeing which account satisfies most of the relevant criteria seems to be particularly reliable, since the meeting of criteria which Aristotle himself has set up, gets Aristotle's explicit endorsement. We will thus see that on Aristotle's ow'n terms the life of theoretical study wins hands down.

I have presented a summary of the results of this investigation in the table below. As can be seen from the table, the life of theo-

(1978), 343-358; Thomas Nagel, “Aristotle on Eudaimonia” originally published in Pluronesis 17 (1972), 252-259; Anthony Kenny, "Happiness", Proceedingss of the Aristotelian Society, 66 (1965-66), 93-102.

4 Such an approach is attempted by, for instance, Amelie Oksenberg Rorty, in "The Place of Contemplation in Aristotle's Nicomachean Ethics," Mind 87 (1978), 343-358; and Kathleen Wilkes in "The Good Man and the Good for Man in Aristotle's Ethics", Mind 87 (1978), 553-571. 
retical study appears to meet a vastly greater number of criteria than its chief competitor, namely, the life of practical activity in accordance with virtues of character and intelligence. (Textual support is cited where reasons might ber equested. I have given the life in accordance with virtues of character and intelligence the benefit of the doubt where Aristotle is not clear.)

Key:

\section{"F" stands for "fulfills the criterion" "NF" stands for "does not fulfill the criterion"}

Necessary Conditions and Reliable Indicator

RI. Such a life expresses freedom//ree choice

R2. Such a life is fitting for a huminn lile

R3. The highest good should not be superticial

R4. The good is something we intuitively believe is hard to take from someone

R5. The good will involve an activity not simply the possession of a state

R6. External goods such is good fortune seem in some wily to be relevint to happiness

R7. No-one chooses happiness for iny reitson other thin itself - it is intrinsically desirable

R8. The good is thit tor the sake of which other things are done

R9. The good is the most complete

$R 10$. The good is most choiceworthy - there is nothing which cin be added to the good which will make it more choiceworthy

R11. The good is self-sufficient - it makes a life most choiceworthy

R12. Happiness is the soul's activity thit expresses virtue and if there is more than one, the best and most complete

RI3. Happiness is to be found in a complete life

RI4. The highest good realizes sone distinctive element in humin nature

R15. The virtue of a human being will be that state which makes him perform his function well

\author{
Happiness $=\mathrm{A}$ Life
} of 'Theoretical Study

F

F: $1178: 15-8$

F: $1177: 115$

F: $1178: 2$

F: $1177 \mathrm{a} 15$

F: $1178: 24-25$

F: $1177 \mathrm{bl}-2$

F: $1177 b 2(1)-21$

F: $1177 b 24-25$

F: $1177 \mathrm{bl}-2$

$F:|177 b| 8-2 \mid$

F: $1177 \mathrm{al}(1)-19 \&$ $1177 \mathrm{~b} 1-2$

F: 1177625

F: $1178: 12-10$

F: $1178: 15-8$
Happiness $=$ A Life

Where Virtues of

Character and

Intelligence are Best

F

$\mathrm{F}$

$\mathrm{F}$

F

F

F

NF: $\quad 1177 b \mid-4$

NF: Not alwatys 1177b/7-1177b18 $\mathrm{N} 1: 1177 \mathrm{~b} \mid 8$ \& $1177 \mathrm{bl}-4$ NF: $|177 \mathrm{~b}| 8 \& 11177 \mathrm{bl}-4$

NF: $1177 \mathrm{~h} 18$

NF: not best not most complete see LHS

F

F

F: $11+4: 17-10$ 
II6. Happiness will be sone good of the soul

117. Happiness is a son of living well and doing well in action

118. It is most pleasant

119. Happiness should not depend too hetivily on external goods

120. Virtue is the controlling elentent of happines:

121. Happiness will consist in those activities we can engige in most fully and continuously

122. The good must not ciluse more ham than benefit: it must not cituse the neglect of our bodies and possessions

123. The pleasures to be experienced trom happiness are of a pure and civilized type

124. The good must be involved with serious mitters

125. The best virtue will correspond to the supreme element in lumans

126. A life of this activity is most selfsufficient $_{2}$ - this activity can be done without needing other people

127. The highest good aims it no end beyond itself

I28. The highest good will require peacetime or leisure

129. The highest good will in some respects emulate a god-like life
$\mathbf{F}$

F

F: $1177: 24$

F: This requires external goods less than the other life \& these can be a hindrance

$1178 a_{2} 4-25$

F

F: $1177: 22-23$

$\mathbf{F}$

NF: Not most pleatsant:

1 177:124

F: Reyuires some external goods to do virtuous actions

$1178 \mathrm{bl}-3$

F

NF: $1177: 122-23$

NF: Not obvious how the 2nd part can be fultilled

F: $1177: 25-26$

F: Adlierence to the mein would not allow such neglect F

F: $1177 a 15$

F

F: $1178 \div 2-8$

NF: 1178:2-8

F: 1177:125-35

NF: | 178:24-1178b3 \& $1178: 11-14$

F: $1177 b 1-2$

NF: $1177 b 2-4$

F: $1177 b 5-22$

NF: $1177 b 5-22$

F: $1177 b 26.33$

$N F: 1178 ; 18-14$

It appears then that the life spent engaging in the activity of theoretical study meets just about all the requirements and reliable indicators Aristotle demands of an adequate account.

The life spent engaging in the activity of theoretical study meets all fifteen of the necessary conditions which an adequate account of happiness must satisfy. Moreover, it satisfies almost all the reliable indicators too (thirteen of the fourteen). There is only one that it does not appear to meet and that is (I22). How will a life of theoretical study preclude the possibility that we will neglect our bodies and possessions? (Perhaps there is some way in which the highest good can satisfy this requirement although it is not obvious.) By contrast, the life of activity in accordance with virtues of 
character and intelligence does not satisfy six of the fifteen necessary conditions an adequate account of the nature of happiness should satisfy to be minimally adequate and does not satisfy seven of the fourteen reliable indicators. A clear choice has thus emerged: the life of theoretical study is the happy life, according to Aristotle.

\section{The big picture once again: summary of the paper's findings}

In this paper I examined the method Aristotle employed in investigating the nature of happiness in NE. I discerned a pattern to the inquiry which I baptized "the onion approach to developing and fleshing out a view". Material for the core was derived from considering some proposals and using ordinary language usage and those common opinions which enjoy unanimity as an appropriate yardstick for sorting those aspects which are true from those which are not. (I discussed why these two sources are to be trusted.) Material was also garnered from certain metaphysical views. Through careful exegesis of this material, a set of requirements (necessary conditions) was derived which any adequate account of the nature of happiness should satisfy. These necessary conditions constitute the core. Through constant testing of the view developed against fresh data, new insights about happiness are extracted. These insights were converted into reliable indicators and they were added to the list of criteria which any adequate account must attempt to satisfy. Thus we saw how the onion got its layers, as layers of insights were revealed through testing new data against the view.

Having collected a good set of criteria by which to judge an adequate account of the highest good, we were then in a position to address the notorious problem that Aristotle appears to endorse two incompatible lives as happy. When we tested the hypothesis that happiness consists in a life engaging in the activity of theoretical study against the criteria already established, we saw that the hypothesis satisfied nearly all the criteria it should and certainly all the necessary ones. By contrast, the chief rival hypothesis, namely the life spent engaging in practical activity in accordance with virtues of character and intelligence, fared miserably when evaluated in terms of the same set of criteria. Since these are the criteria Aristotle himself demanded of an adequate view, we can 
conclude that Aristotle himself endorsed the hypothesis that happiness consists in a life engaging in the activity of theoretical study. 5

5 I am very grateful to Michael Ferejohn for comments on this paper, and for his offering a course on the Nicomachean Ethics to accommodate my interest in studying this text in detail. 